\title{
The Empirical Analysis for Resident's Marginal Propensity in Shanghai Suburbs
}

\author{
Tianlang Li, Lei Zhou \\ Department of Business, University of Shanghai Dianji, Shanghai 201306, China \\ tianlang_lee@outlook.com, zhouleikeai@outlook.com
}

\begin{abstract}
The improvement of marginal propensity is the key to boost domestic consumption and to expand domestic consumption. From the empirical studies on residents' marginal propensity in Shanghai suburbs, an fluctuating descending tendency from 2010 to 2011 can be found. Thus the marginal propensity to consume should be enhanced by keeping the stability of macroeconomic policy, increasing rural incomes, enlarging the financial investment in rural education, health, pension, etc, and the like.

Index Terms - Marginal propensity to consume, suburban of Shanghai
\end{abstract}

\section{Introduction}

It is well known that consumption, investment and exportation are "three carriages" of driving economic growth, and the consumption is the most direct response for demand of residents. The consumption can be considered to be the most important carriage not only because of it occupies a very important position in GDP accounting, but also because of it has a significant impact on investment and exports through the multiplier effect.

Since seventy-seven years ago, the British economist John Maynard Keynes proposed theories about the consumption function in his "The General Theory of Employment, Interest, and Money" that triggered a series of research and exploration about the relationship between consumption and income. The American economist J.S.Duesenberry presents relative income consumption theory, that he believes consumption and income maintain a relatively fixed rate in the long term, and therefore the long-term consumption curve is a straight line from the origin; while in the short term, consumption will increases with the increase of revenues but hard to decrease with the decrease of revenue, then the short-term consumption curve is a positive intercept. So while consumers be affected by their consumption habits, they influenced by the surrounding consumption environment [1]. Also Franco Modigliani et al proposed the life cycle hypothesis theory of investment and saving.Considering from the microscopic view of consumer behaviour, families and individuals plan their spending based on the whole life income expectation, and the consumption of families and individuals depend on the total revenue and property earned during the life cycle. American economist Milton Friedman has proposed a permanent income theory of consumption, that consumers' spending is not primarily determined by his time limited income, but by his permanent income. Permanent income is long-term revenues that he consumer can expect. [1]

Our research in this area started relatively late, Jianguo Liu (1999) found that the propensity to consume among farmers was generally low. Yongding Yu, Li Jun (2000) analyzed consumption characteristics of rural residents from the angle that household saving were limited by liquidity. Then came to the empirical research, Shucai Ma et al (2006), according to the modern consumer theory, established the variable error correction model with the variables of total real income and consumption for Chinese farmers. In 2007, Jiangpeng Lin and them created and used OLS method to estimate the linear consumption function on the basis of Keynesian theory and the absolute income hypothesis consumption function mode theory. Through the comparison of urban and rural residents 'consumption function, reached the following conclusion: our farmers' income and consumer spending levels were highly positively correlated. Income is the most direct and decisive factor that impact on farmers' consumption. Through the income consumption data of rural residents from 1978 to 2004, Jia Luo (2007) established the error correction model and investigated the degree impact that consumption was affected by different sources income. In 2009, Bao Chen et al fulfilled the empirical analysis on China's urban and rural residents consumption classified by income with the help of quantile regression, the results showed that: resident's income gap is indeed an important factor restricting Chinese domestic demand, marginal propensity to consume are different in different income strata[2].

2. The empirical analysis for resident's marginal propensity in Shanghai suburbs

A. Data Sources and Method of Calculating the Marginal Propensity to Consume

For the calculation of the marginal propensity to consume, there are many ways. However, four of the most important and most direct method are: using consumption rate instead of marginal propensity to consume, asking the marginal propensity to consume with a first difference as the comparison (definition method), using the linear expansion model ELES to calculate marginal propensity to consume, and fitting marginal propensity to consume through the consumption function model[3]. Among them, the method of asking the marginal propensity to consume with a first difference as the comparison is convenient, fast and more accurate. Therefore we use the formula:

$$
M P C=b=\frac{\Delta C}{\Delta Y}
$$


calculating directly the value of the marginal propensity to consume, and to observe the changes in trends and characteristics.

In order to investigate deeply the characteristics, change patterns and trends of resident's marginal propensity in Shanghai suburbs, we will use the per capita disposable income and per capita consumption expenditure of Shanghai rural residents during 2000-2011 catched from "Shanghai Statistical Yearbook" obtained from sample survey by the National Bureau of Statistics Shanghai Statistical Office, combined with the formula above to calculate the marginal propensity to consume of Shanghai rural residents from 2003 to 2011[4].

TABLE I Shanghai rural resident's per capita disposable income and per capita consumption expenditure from 2000 to 2011

\begin{tabular}{|c|c|c|}
\hline Years & $\begin{array}{c}\text { per capita disposable income } \\
\text { (yuan) }\end{array}$ & $\begin{array}{c}\text { per capita consumption expenditure } \\
\text { (yuan) }\end{array}$ \\
\hline 2000 & 5565 & 4138 \\
\hline 2001 & 5850 & 4753 \\
\hline 2002 & 6212 & 5311 \\
\hline 2003 & 6658 & 5670 \\
\hline 2004 & 7337 & 6329 \\
\hline 2005 & 8342 & 7265 \\
\hline 2006 & 9213 & 8006 \\
\hline 2007 & 10222 & 8845 \\
\hline 2008 & 11384 & 9115 \\
\hline 2009 & 12324 & 9804 \\
\hline 2010 & 13746 & 10225 \\
\hline 2011 & 15644 & 11272 \\
\hline
\end{tabular}

B. Using the Definition Method to Ask the Marginal Propensity to Consume of Each Year with a First Difference as the Comparison

To use the data in Table I, calculate adjacent years' change in disposable income and per capita consumption expenditure of according to the definition method, then do comparison to calculate the following marginal propensity to consume values for each year.

TABLE II Shanghai rural resident's marginal propensity to consume from 2001 to 2011

\begin{tabular}{|c|c|}
\hline Years & MPC \\
\hline 2001 & 2.157894737 \\
\hline 2002 & 1.541436464 \\
\hline 2003 & 0.804932735 \\
\hline 2004 & 0.957290133 \\
\hline 2005 & 0.931343284 \\
\hline 2006 & 0.850746269 \\
\hline 2007 & 0.831516353 \\
\hline 2008 & 0.232158212 \\
\hline 2009 & 0.733759318 \\
\hline 2010 & 0.296061885 \\
\hline 2011 & 0.551633298 \\
\hline
\end{tabular}

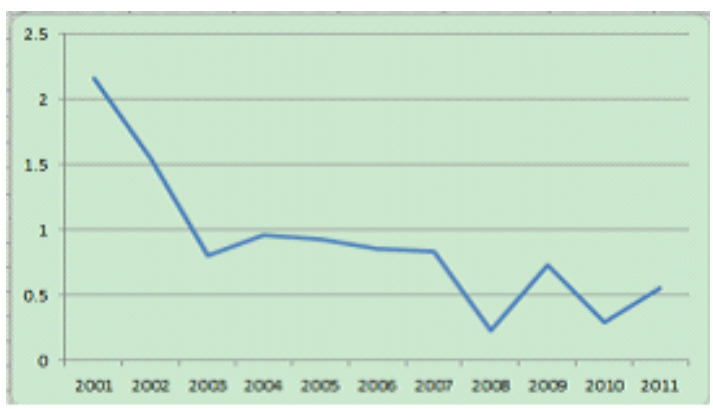

Fig. 1 Shanghai rural marginal propensity to consume (MPC) trends from 2001 to 2011

\section{Data Analysis}

From 2001 to 2002, the marginal propensity to consume in Shanghai rural areas is greater than zero; in the meantime there is a certain growth in residents per capita disposable income compared to the previous year, the growth rate is $5.1 \%$ and $6.2 \%$. However, relative to disposable income, per capita consumption expenditure growth rate even more. Especially every hundred households has a significant increase in durable consumer. More noteworthy is the change in consumption structure. From 2000 to 2002, food consumption of rural residents in Shanghai has dropped by nearly ten percent in the consumption structure. The consumption ratio in housing, transport, communications, cultural and educational entertainment products, services and other aspects has increased significantly. Moreover, this is a period of many important events in Shanghai's development and opening. This period is an important event in the development and opening Shanghai section. Data shows that during this period life levels of rural residents have been significantly improved. At the same time, Shanghai rural residents maintain a high marginal propensity to consume which has played an irreplaceable role in Shanghai's rapid economic development.

From 2003 to 2007, Shanghai rural residents' marginal propensity to consume continue to maintain a high level, but overall there is a downward tendency. In this range, rural residents' per capita disposable income and per capita consumption expenditure still upgraded at a high speed, just in a few years the per capita disposable income of rural residents raised from 6212 yuan raised to 10,222 yuan, and disposable consumer spending also improved from 5311 yuan to 8845 yuan. On the one hand this must benefited from the stable implementation of China's economic reform policies, the basic operating system in rural areas has been steady improvement, and the Chinese government has given farmers the more fully and secure land contract management rights. On the other hand, after joining the WTO, Shanghai has a broader agricultural market that provided a new space for moderatescale agricultural development. Meanwhile, compared with other parts of China, Shanghai rural areas have a relatively good economic interaction with urban, which played an important role in the improvement of rural residents living standards.

During 2008 to 2011, the marginal propensity to consume of Shanghai rural residents affected by short-term price 
fluctuations and other factors shows a strong fluctuating. Although the per capita disposable income and consumption expenditure shows a steady growth trend, but the change in the value of the marginal propensity to consume is great. In this period the inflation caused by blind expansionary fiscal policy influenced rural residents a lot. In addition, the problems accumulated in China's economic transition process: social security, pension insurance, rural land ownership and others epitomize out. Therefore, although Shanghai rural residents per capita disposable income is increasing, residents are faced with greater uncertainty respect to the past, which makes the consumption tendency value of rural residents tend to a strong fluctuations with rapid decrease.

\section{Conclusions and Policy Recommendations}

Through the analysis of changes in the above data we can find the marginal propensity to consume of Shanghai rural residents shows a fluctuate downward tendency, and a turbulent state after 2007. This will not only lead to the lack of demand and consumption stagnation or others, but also goes against the long-term stable development of the economy. Under the premise that rural residents facing tremendous uncertainty because of many reasons, government's blind stimulus of spending often difficult to work. In order to respond to and improve this situation, we recommend the
Government from the following aspects: First, maintain the stability of macroeconomic policies to avoid greater shortterm price fluctuations. Second, continue to make efforts to increase rural incomes and standardize the distribution of wealth through adjusting macro allocation target, to ensure that rural residents can reasonably share the fruits of reform. Third, increase financial expenditure in rural education, health care, pension and other aspects for rural residents to reduce the uncertainty they face in the long run. Fourth, attempt to implement the rural consumer credit business in order to stimulate consumption. Rural residents to restore consumer confidence and the marginal propensity to consume stable recovery. Hoping a restore of rural residents' consumer confidence and a stable recovery of the marginal propensity to consume.

\section{References}

[1] Hongye Gao, "Western economics (macro part)", China Renmin University Press, Fifth Edition, 2011.p389-391.

[2] Mali Guo, "The Income Price and the Marginal Propensity to Consume of Review", Shang Qing, vol. 44, 2012.

[3] Liang Wang, "Several existing calculation methods Analysis for China's marginal propensity to consume", Statistics and Information Forum, vol.20, 2005.

[4] “Shanghai Statistical Yearbook", China Statistics Press.2000-2011 